\title{
Plasma Renin and Angiotensinogen Levels in Pathological States Associated with Oedema
}

\author{
MASASHI IMAI* and HIROFUMI SOKABE \\ From the Department of Paediatrics, University of Tokyo, and the Department of Pharmacology, \\ Toho University School of Medicine
}

It is now generally accepted that hyperaldosteronism is associated with such oedematous states as the nephrotic syndrome, cirrhosis of the liver, and congestive heart failure (Wolff et al., 1964); that the renin-angiotensin system plays an important role in the regulation of aldosterone secretion (Genest et al., 1960; Laragh et al., 1960; Carpenter, Davis, and Ayers, 1961 ; Bartter et al., 1961 ; BlairWest et al., 1962; Davis, 1962); and that plasma renin activity is increased in oedematous conditions (Yoshinaga et al., 1963; Brown et al., 1964; Veyrat et al., 1964; Fasciolo et al., 1964; Ayers, 1967). On the other hand, little is known about the angiotensinogen levels which influence the plasma renin activity values as determined by available methods (Yoshinaga et al., 1963; Warzynski, Demirjian, and Hoobler, 1964; Boucher et al., 1964 ; De Vito and Fasciolo, 1965; Pickens et al., 1965).

The present communication reports simultaneous determinations of plasma renin and angiotensinogen levels in several pathological conditions associated with oedema and ascites, and discusses the role of the renin-angiotensin system in these conditions. The effect of the increase in blood pressure on the plasma renin concentration was studied in several renal disorders associated with hypertension.

\section{Materials and Methods}

The present study included 7 patients with the nephrotic syndrome; 7 with acute glomerulonephritis, 2 of whom were oedematous at the time of examination; 9 with chronic renal diseases, including glomerulonephritis, pyelonephritis, and hypoplastic kidney, all except one of whom were without oedema; 9 with cirrhosis of the liver caused by Wilson's disease or congenital bile-duct atresia; 5 with liver disease without cirrhosis; 2 with congestive heart failure; and 2 with protein-losing enteropathy. All the patients were under 15 years of

\footnotetext{
Received March 12, 1968.

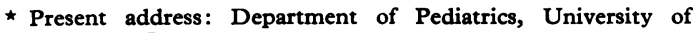
Tokyo, Tokyo, Japan.
}

age (range 3 months-15 years). 17 samples from 16 normal subjects aged between 3 months and 28 years served as controls.

In the patients with the nephrotic syndrome, a blood sample was drawn under three different conditions: (i) during the initial phase, when the patients showed generalized oedema before being treated by sodium restriction and steroids; (ii) during the diuretic phase, when generalized oedema and proteinuria had disappeared under steroid therapy and while the patients were still on a salt-restricted diet; and (iii) during the convalescent phase, when such biochemical abnormalities as hypercholesterolaemia and hypoproteinaemia had subsided and the patients were receiving intermittent steroid therapy and an ordinary diet.

The controlled diet for the treatment of oedema was graded according to its salt content as: (1st degree), a low salt diet, containing about 10 to $30 \mathrm{mEq}$ sodium chloride per day; (2nd degree), a mildly restricted diet, containing 30 to $80 \mathrm{mEq}$ sodium chloride per day; and (3rd degree), no restriction of salt.

Plasma renin concentration was determined as reported elsewhere (Imai and Sokabe, 1967). The method was based on that of Boucher et al. (1964), modified as follows: (a) amounts of Dowex 50W-X2 resin and of the reagents were reduced to compensate for the small amounts of plasma obtainable from infants and children; (b) the final eluate was not acidified by acetic acid but was evaporated immediately to dryness; and the final dry residue was dissolved in $0.6 \mathrm{ml} .0 .9 \%$ saline; (c) the values of plasma renin concentration were expressed as $\mathrm{K}$, the constant of a first order reaction. According to Helmer and Judson (1963), this $K$ is equivalent to a Goldblatt unit per ml. plasma.

Angiotensinogen concentrations were determined as previously reported (Imai and Sokabe, 1967): to $0 \cdot 1 \mathrm{ml}$. plasma adjusted to $\mathrm{pH} 5 \cdot 5$ was added an excess amount of renin prepared from human kidney extract, $0.2 \mathrm{ml}$. $3.8 \%$ ammonium EDTA, and $1.0 \mathrm{ml} .0 \cdot 2 \mathrm{M}$ ammonium acetate buffer $(p \mathrm{H} 6 \cdot 0)$, and the mixture was incubated with $2 \mathrm{ml}$. Dowex $50 \mathrm{~W}-\mathrm{X} 2$ renin $\left(\mathrm{NH}_{4}+\right.$ form) at $37^{\circ} \mathrm{C}$. for 2 hours. The method to elute angiotensin was the same as mentioned above. Plasma angiotensinogen level was expressed as nanograms of angiotensin per $\mathrm{ml}$. plasma. 


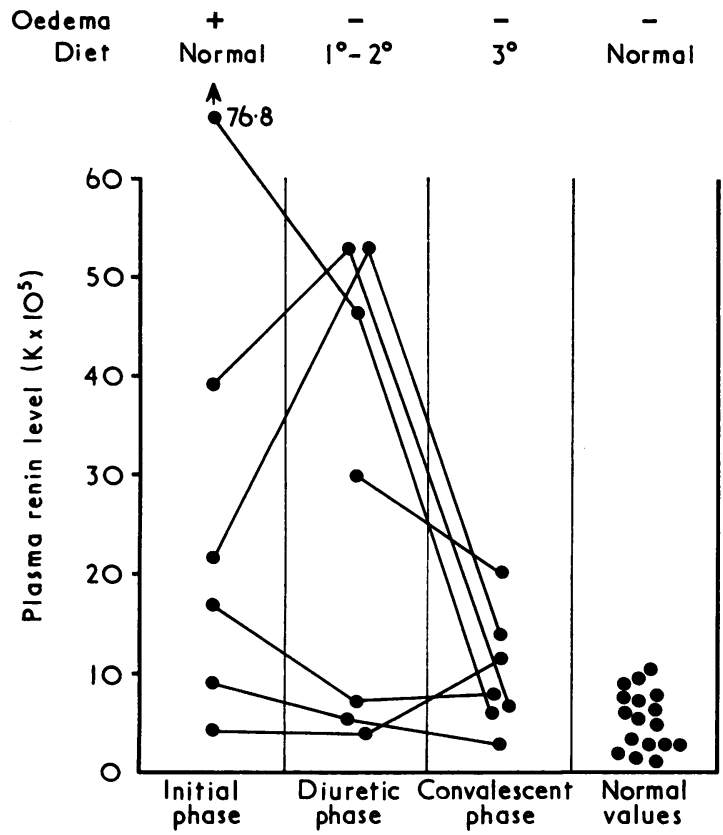

FIG. 1.-Changes in plasma renin levels during various phases of the nephrotic syndrome.

\section{Results}

Normal subjects. The mean plasma renin level $\left(\mathrm{K} \times 10^{5}\right)$ of 16 normal subjects was $5 \cdot 7 \pm 3 \cdot 2$ (SD), ranging from $1 \cdot 4$ to $11 \cdot 3$, with a $95 \%$ confidence limit of $3 \cdot 7$ to $7 \cdot 1$. The mean angiotensinogen level in the same subjects was $294 \pm 129$ (SD) $\mathrm{ng} . / \mathrm{ml}$. ranging from 99 to $555 \mathrm{ng} . / \mathrm{ml}$., with a $95 \%$ confidence limit of 227 to $361 \mathrm{ng} . / \mathrm{ml}$.
Nephrotic syndrome. The plasma renin levels during the course of the disease are summarized in Fig. 1 and the Table. In the initial phase before treatment, plasma renin levels were raised in 4 of the 6 patients. After disappearance of the oedema, 3 patients showed a gradual decrease in plasma renin concentrations, but 2 showed a further increase. Plasma renin remained significantly raised during this diuretic phase. In the convalescent phase, it returned to normal levels.

Changes in angiotensinogen levels in these patients were more striking, as shown in Fig. 2 and the Table: with one exception, all showed a similar change in angiotensinogen throughout the course of the disease. In the initial phase, angiotensinogen was significantly lower than in the normal subjects. In the diuretic phase, it was increased, but returned towards normal during the convalescent phase.

No correlation was observed between plasma renin and angiotensinogen levels during the nephrotic syndrome.

Liver disease. The plasma renin concentration in various liver diseases, as shown in the Table, was increased in patients with cirrhosis of the liver with ascites. A moderate increase was also noted in cirrhotics without ascites. Plasma renin level in the miscellaneous liver diseases without cirrhosis was within normal limits.

Angiotensinogen levels tended to decline with increased severity of the cirrhosis. An inverse correlation was observed between the logarithmic values of the angiotensinogen and the plasma renin concentrations (Fig. 3).

TABLE

Plasma Renin and Angiotensinogen Levels in Various Clinical Conditions

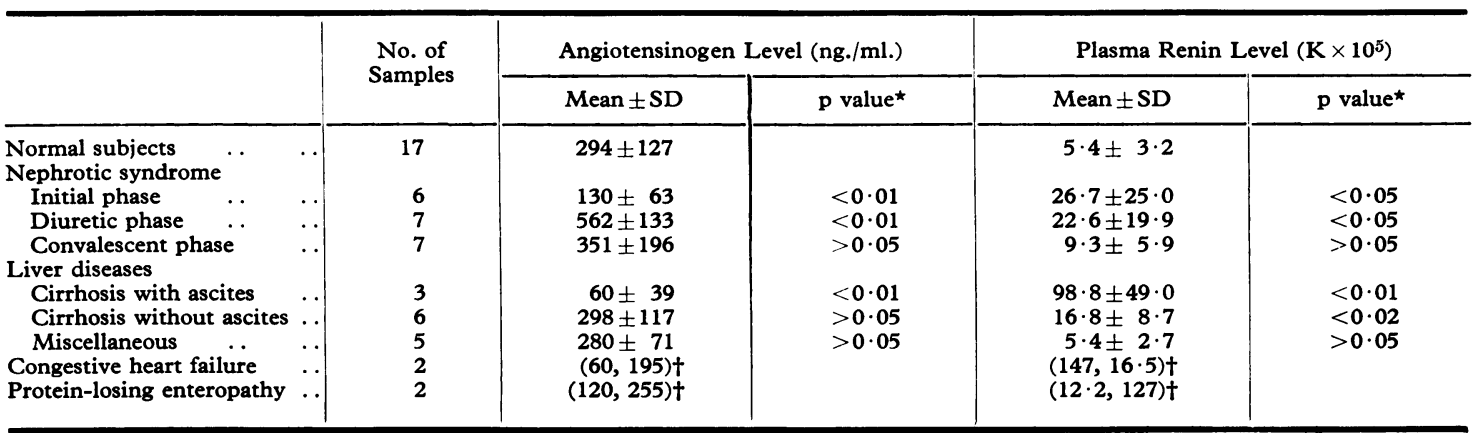

* p values lower than 0.05 indicate the significance of the differences from the normal.

+ These represent individual values. 


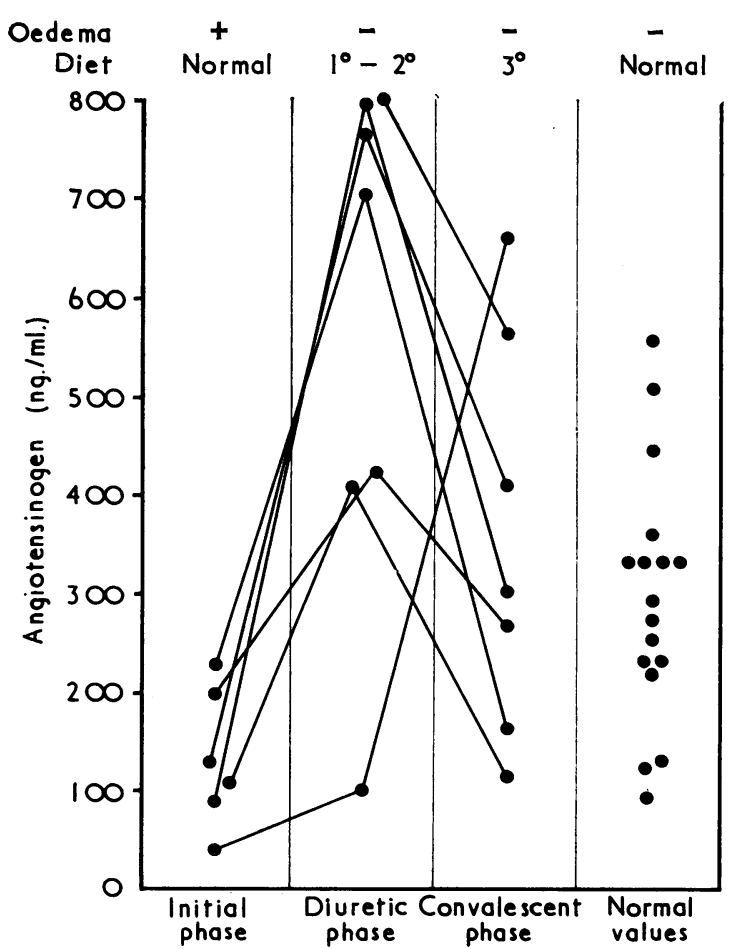

FIG. 2.-Changes in plasma angiotensinogen levels during various phases of the nephrotic syndrome.

Miscellaneous conditions associated with oedema or ascites. In 2 cases of congestive heart failure, plasma renin concentration was 147

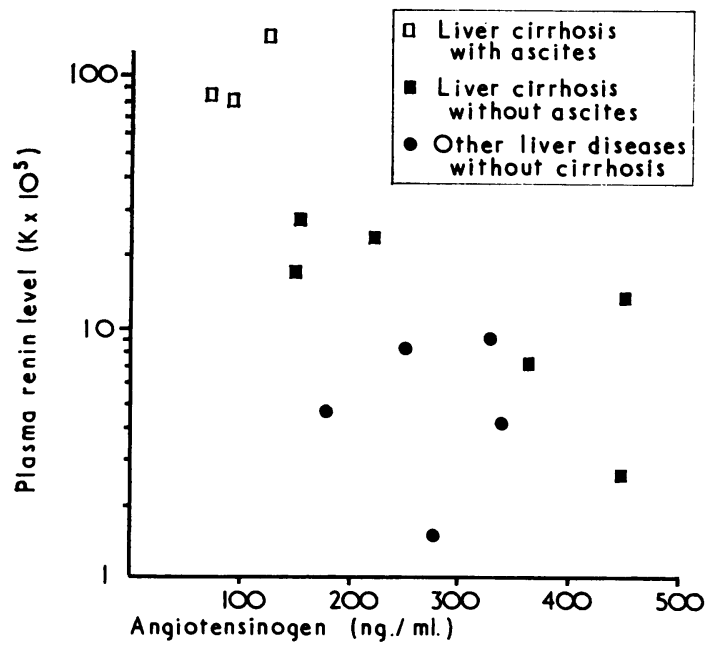

FIG. 3.-Correlation of angiotensinogen levels with the logarithm of plasma renin levels in liver diseases. and $16 \cdot 5$, respectively. In two cases of proteinlosing enteropathy, it was $12 \cdot 2$ and 127 , respectively.

Acute glomerulonephritis and chronic renal diseases. Plasma renin levels in diffuse parenchymatous renal diseases other than the nephrotic syndrome are shown in Fig. 4, with special reference to hypertension. Hypertension was defined as pressures above $150 \mathrm{~mm}$. $\mathrm{Hg}$, systolic, and $90 \mathrm{~mm}$. $\mathrm{Hg}$, diastolic, regardless of age. In the hypertensive group, plasma renin level tended to be suppressed even in patients with oedema or under salt restric-

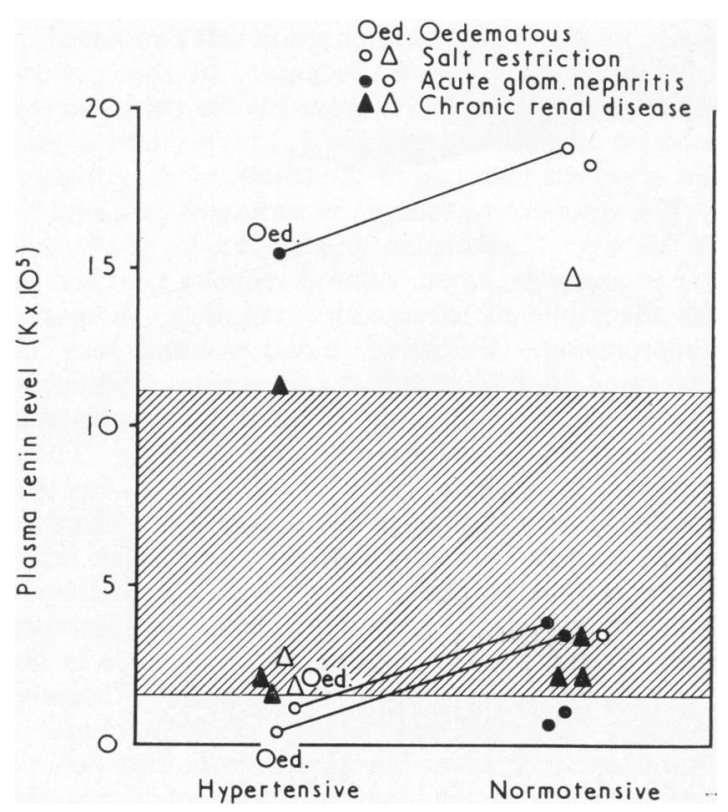

FIG. 4.-Plasma renin levels in renal diseases with and without hypertension. Shaded area indicates the normal range.

tion. In the majority of the normotensive group on ordinary diet, it was in the lower limit of normal. An increase in plasma renin concentration was noted only when salt intake was restricted.

\section{Discussion}

The present investigation confirms earlier observations that plasma renin activity is increased in the oedematous states associated with the nephrotic syndrome, liver cirrhosis, and congestive heart failure (Yoshinaga et al., 1963; Brown et al., 1964; Veyrat et al., 1964; Fasciolo et al., 1964; Ayers, 
1967). Two cases of protein-losing enteropathy with generalized oedema and ascites also showed an increase in plasma renin concentration. Studies indicate that experimental or pathological conditions associated with a reduction of 'effective' blood volume stimulate aldosterone secretion (Bartter, 1956; Davis, 1962). It is probable that secondary hyperaldosteronism in these oedematous states results from increased activity of the reninangiotensin system induced by a reduction of 'effective' blood volume.

In the initial phase of the nephrotic syndrome, the increase in plasma renin concentration was associated with generalized oedema. In the diuretic phase, plasma renin concentration was also raised in spite of the absence of oedema. In this period, salt restriction may be responsible for the observed increase in plasma renin level. Hypertension was not observed throughout the course of the disease.

The total blood volume is increased in cirrhosis of the liver (Lieberman and Reynolds, 1967), but the increase in blood volume may be confined to the hepatolienal circulation, resulting in portal hypertension. 'Effective' blood volume may be decreased in this condition, because a diminished glomerular filtration rate is often associated with liver cirrhosis (Lancestremere et al., 1962). Thus, increase in plasma renin concentration in this condition may be due to the decrease in 'effective' blood volume. It is of interest that plasma renin concentration is also increased in liver cirrhosis without ascites. Decrease in metabolic clearance rate of renin may be a cause of the increase in the plasma renin level in liver cirrhosis. Recently, Heacox, Harvey, and Vander (1967) found a significant difference between arterial and hepatic venous renin in the dog, and concluded that the liver was the major site of renin inactivation.

An increased activity of the renin-angiotensin system seems to be a compensatory mechanism to restore the diminished 'effective' blood volume, rather than a cause of oedema, because plasma renin concentration is also increased in such conditions as the diuretic phase of the nephrotic syndrome, or liver cirrhosis without ascites.

Angiotensinogen or renin substrate is a protein that migrates with $\alpha_{2}$-globulin. Although the normal values of the angiotensinogen levels reported in this study are somewhat lower than those reported by others (Aida et al., 1965; Gould, Skeggs, and Kahn, 1966), relative values are significant among various conditions. In the initial phase of the nephrotic syndrome, it was significantly reduced. This is consistent with the observation of Aida et al. (1965), and may reflect the hypoproteinaemia in this state. Angiotensinogen concentration was also decreased in liver cirrhosis with ascites: this accords with that of Ayers (1967), and suggests that plasma angiotensinogen level is closely related to protein metabolism. It may be influenced also by the levels of plasma renin activity, because a marked increase in angiotensinogen has been reported in nephrectomized rats (Sokabe et al., 1965). The present investigation has shown that angiotensinogen is increased in the diuretic phase of the nephrotic syndrome. The underlying mechanism is open to question. Increased protein metabolism may be one factor.

Variations of angiotensinogen in various conditions would influence the formation of angiotensin when the plasma is incubated in vitro, because the enzymatic reaction of renin on angiotensinogen is dependent on the concentration of substrate, as reported elsewhere (Imai and Sokabe, 1967). The formation of angiotensin does not reflect accordingly the true renin concentration. The expression by the first order reaction constant is recommended in order to eliminate the influence of changes in plasma angiotensinogen levels.

The finding that the plasma renin level is suppressed in diffuse renal diseases with hypertension is inconsistent with the observation of Massani et al. (1966), who reported that plasma angiotensin levels were high in acute glomerulonephritis with hypertension. However, decreased activity of the renin-angiotensin system has been observed in several pathological conditions associated with hypertension (Helmer, 1964; Brown et al., 1965; Kawabe and Sokabe, 1966), and in spontaneously hypertensive rats (Sokabe, 1966). We would like to emphasize that plasma renin levels are decreased when hypertension is present, even in conditions associated with oedema or during salt restriction. Consequently, the high blood pressure also acts as a negative feedback stimulus to the juxtaglomerular apparatus.

\section{Summary}

Plasma renin and angiotensinogen levels were determined in several pathological conditions associated with oedema. Plasma renin concentration was significantly increased in patients with the nephrotic syndrome and generalized oedema. It was also raised in patients without oedema on salt restriction. In cirrhosis of the liver, a marked increase in plasma renin concentration was noted when ascites was present. In those without ascites, it was also raised significantly. In patients in congestive heart failure or suffering from proteinlosing enteropathy, increased plasma renin concen- 
tration was associated with generalized oedema. In acute and chronic renal diseases with hypertension, plasma renin levels were decreased. Angiotensinogen levels were decreased in the initial phase of the nephrotic syndrome and in cirrhosis of the liver with ascites. It was increased considerably during the diuretic phase of the nephrotic syndrome

The authors wish to express their thanks to Professor Tadao Takatsu for his help in analysing the data.

\section{REFERENCES}

Aida, M., Maebashi, M., Yoshinaga, K., and Ichinohe, F. (1965). Estimation of plasma renin and renin-substrate in various diseases in man. Tohoku $\mathcal{F}$. exp. Med., 87, 35.

Ayers, C. R. (1967). Plasma renin activity and renin-substrate concentration in patients with liver disease. Circulat. Res., 20, 594.

Bartter, F. C. (1956). The role of aldosterone in normal homeostasis and in certain disease states. Metabolism, 5, 369.

-, Casper, A. G. T., Delea, C. S., and Slater, J. D. H. (1961). On the role of the kidney in control of adrenal steroid production. ibid., 10, 1006.

Blair-West, J. R., Coghlan, J. P., Denton, D. A., Goding, J. R., Munro, J. A., Peterson, R. E., and Wintour, M. (1962). Humoral stimulation of adrenal cortical secretion. $\mathcal{F}$. clin. Invest., 41, 1606.

Boucher, R., Veyrat, R., De Champlain, J., and Genest, J. (1964). New procedures for measurement of human plasma angiotensin and renin activity levels. Canad. med. Ass. F., 90, 194.

Brown, J. J., Davies, D. L., Lever, A. F., and Robertson, J. I. S. (1964). Variations in plasma renin concentration in several physiological and pathological states. Canad. med. Ass. F., 80, 201.

,,-- , and $-(1965)$. Plasma renin concentration in Brit. med. F., 2, 1215.

Carpenter, C. C. J., Davis, J. O., and Ayers, C. R. (1961). Relation of renin, angiotensin II, and experimental renal hypertension to aldosterone secretion $\mathcal{F}$. clin. Invest., 40, 2026.

Davis, J. O. (1962). The control of aldosterone secretion. Physiologist, $5,65$.

De Vito, E., and Fasciolo, J. C. (1965). A method for the estimation of renin activity in plasma. Acta physiol. lat.-amer., 15, 129.

Fasciolo, J. C., De Vito, E., Romero, J. C., and Cucchi, J. N. (1964). The renin content of the blood of humans and dogs under several conditions. Canad. med. Ass. F., 90, 206.

Genest, J., Nowaczynski, W., Koiw, E., Sandor, T., and Biron, P. (1960). Adrenocortical function in essential hypertension.
In Essential Hypertension. An International Symposium, p. 126. Ed. by E. Buchborn and K. D. Bock. Springer, Berlin.

Gould, A. B., Skeggs, L. T., and Kahn, J. R. (1966). Measurement of renin and substrate concentrations in human serum. Lab. Invest., 15, 1802.

Heacox, R., Harvey, A. M., and Vander, A. J. (1967). Hepatic inactivation of renin. Circulat. Res., 21, 149.

Helmer, O. M. (1964). Renin activity in blood from patients with hypertension. Canad. med. Ass. F., 80, 221.

- , and Judson, W. E. (1963). The quantitative determination of renin in the plasma of patients with arterial hypertension. Circulation, 27, 1050.

Imai, M., and Sokabe, H. (1967). A method for the determination of plasma renin activity in small samples. Fap. Heart f., 8, 607 .

Kawabe, K., and Sokabe, H. (1966). Renin content of the kidney in renal and adrenal diseases associated with hypertension. Surgery, 60, 986.

Lancestremere, R. G., Davidson, P. L., Earley, L. E., O'Brien, F. J., and Papper, S. (1962). Renal failure in Laennecs cirrhosis. II. Simultaneous determination of cardiac output and renal hemodynamics. f. clin. Invest., 41, 1922.

Laragh, J. H., Angers, M., Kelly, W. G., and Lieberman, S. (1960). Hypertensive agents and pressor substances. The effect of epinephrine, norepinephrine, angiotensin II, and others on the secretory rate of aldosterone in man. f. Amer. med. Ass., 174, 234.

Lieberman, F. L., and Reynolds, T. B. (1967). Plasma volume in cirrhosis of the liver: its relation to portal hypertension, ascites, and renal failure. F. clin. Invest., 46, 1297.

Massani, Z. M., Finkielman, S., Worcel, M., Agrest, A., and Paladini, A. C. (1966). Angiotensin blood levels in hypertensive and non-hypertensive diseases. Clin. Sci., 30, 473.

Pickens, P. T., Bumpus, F. M., Lloyd, A. M., Smeby, R. R., and Page, I. H. (1965). Measurement of renin activity in human plasma. Circulat. Res., 17, 438.

Sokabe, H. (1966). Renin activity of the kidney in the spontaneously

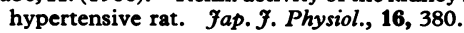

—-, Shibayama, F., Mizogami, S., and Sakai, F. (1965). Cardiovascular reactivity after bilateral nephrectomy in rats. $\mathcal{F} a p$. Heart F., 6, 233.

Veyrat, R., de Champlain, J., Boucher, R., and Genest, J. (1964). Measurement of human arterial renin activity in some physiological and pathological states. Canad. med. Ass. F., 80, 215.

Warzynski, R., Demirjian, Y., and Hoobler, S. (1964). A method for the determination of 'renin' in blood and some preliminary findings. ibid., 80, 225.

Wolff, H. P., Lommer, D., Jahnecke, J., and Torbica, M. (1964). Hyperaldosteronism in oedema. In Aldosterone. A Symposium, p. 471. Ed. by E. E. Baulieu and P. Robel. Blackwell, Oxford.

Yoshinaga, K., Aida, M., Maebashi, M., Sato, T., Abe, K., and Miwa, I. (1963). Assay of renin in peripheral blood: a modification of Helmer's method for the estimation of circulating renin. Tohoku F. exp. Med., 80, 32. 